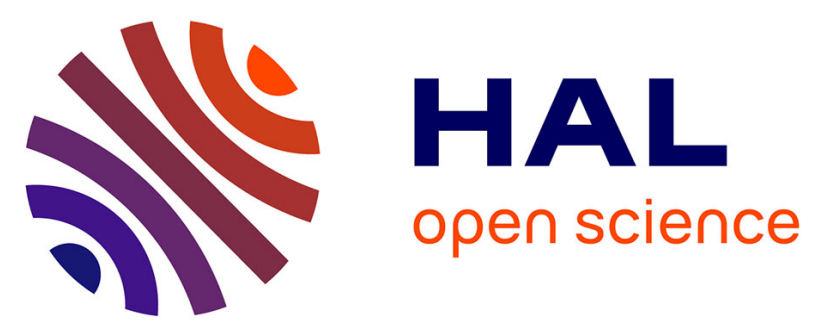

\title{
Numerical Simulation of a Pump-Turbine Transient Load Following Process in Pump Mode
}

\author{
Giorgio Pavesi, Giovanna Cavazzini, Guido Ardizzon
}

\section{To cite this version:}

Giorgio Pavesi, Giovanna Cavazzini, Guido Ardizzon. Numerical Simulation of a Pump-Turbine Transient Load Following Process in Pump Mode. "16th International Symposium on Transport Phenomena and Dynamics of Rotating Machinery (ISROMAC 2016), Apr 2016, Honolulu, United States. hal-01522027

\section{HAL Id: hal-01522027 \\ https://hal.science/hal-01522027}

Submitted on 12 May 2017

HAL is a multi-disciplinary open access archive for the deposit and dissemination of scientific research documents, whether they are published or not. The documents may come from teaching and research institutions in France or abroad, or from public or private research centers.
L'archive ouverte pluridisciplinaire HAL, est destinée au dépôt et à la diffusion de documents scientifiques de niveau recherche, publiés ou non, émanant des établissements d'enseignement et de recherche français ou étrangers, des laboratoires publics ou privés. 


\title{
Numerical Simulation of a Pump-Turbine Transient Load Following Process in Pump Mode
}

\author{
Giorgio Pavesi ${ }^{1 *}$, Giovanna Cavazzini, Guido Ardizzon
}

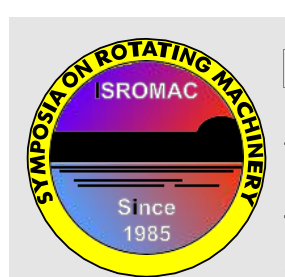

ISROMAC 2016

International Symposium on Transport Phenomena and Dynamics of Rotating Machinery quency.

Hawaii, Honolulu

April 10-15, 2016

\section{Abstract}

This paper presents the simulation of the dynamic behaviour of variable speed pump-turbine. A power reduction scenario at constant wicket gate opening was numerically analysed from $100 \%$ to $93 \%$ rpm corresponding to a power reduction from full load to about $70 \%$ with a ramp rate of $1.5 \%$ per second.

The flow field analysis led to the onset and development of unsteady phenomena progressively evolving in an organized rotating partial stall during the pump power reduction. These phenomena were characterized by frequency and time-frequency analyses of several numerical signals (pressure, blade torque, flow rate in blade passages). The unsteady pattern in return channel strengthened emphasizing its characteristic frequency with the rotational velocity decreasing reaching a maximum and then disappearing. At lower rotational speed, the flow field into the wickets gates channel start to manifest a full three-dimensional flow structure. This disturbance was related to the boundary layer separation and stall and it was noticed by a specific fre-

\section{Keywords}

Adjustable speed hydro plants, dynamic response of hydro plants, hydro plant control

\footnotetext{
${ }^{1}$ Department of Industrial Engineering, University of Padova, Padova, Italy

*Corresponding author: giorgio.pavesi@unipd.it
}

\section{INTRODUCTION}

Word is faced with a complex and challenging restructuring of its energy system. Many countries have agreed to undertake major cuts in its greenhouse gas emissions and to increase power generation from renewable resources, experiencing an increased power production from intermittent sources such as small hydropower, wind power and PV power plants.

Renewable energy is extremely variable and a large share of it is a challenge for the stability of the transmission system, as well as security of supply for the consumers. There is a need for back up capacity to generate power during high demand, as well as a need for storage capacity for surplus power.

Pump-turbine units have become nowadays an interesting way to increase stability of electrical power networks due to their high level of operating flexibility. The main applications of pumped storage are load shifting, price arbitrage, primary and secondary reserves, peak power supply, grid congestion avoidance, load following, and for supporting variable electricity generation [1]. Moreover, According to Joint Research Centre EU [2], pumped hydropower storage is currently the only widespread electricity storage technology able to offer the large-scale storage that is needed for accommodating renewable electricity under the 2020 EU energy targets [3].

The traditional pump-turbine equipment design is the reversible single-stage Francis pump-turbine, which acts as a pump in one direction and as a turbine in the other. On a conventional unit, pumping occurs at a fixed speed and almost fixed wicket gate opening. The power input is nearly constant at the input rating of the pump and the discharge varies with the pumping head. Although this technology is proven and has worked well for over six decades, there are limitations to its performance. Adjustable-speed machines enable the power consumed in the pumping mode to be varied over a range of outputs.

Consistently, an adjustable speed-pumping unit can operate over a larger head range and pumping power input range than a single speed unit and offer several advantages for both pumping and generating modes [4-9] such as:

a) possibility of active power control in pumping mode;

b) efficiency increase and wide range of operation in generating mode especially under partial load;

c) network stability improvement by reactive power control;

d) network stability improvement by instantaneous active power injection in the grid (flywheel effect);

This flexibility is frequently employed by adjusting the speed of units during light load periods over a load range of 50 to $60 \%$ of rated pumping power. This means that a unit does not have to wait until a block of power equal to its full pump capacity rating is available before pumping can begin. Thus, there are more opportunities to purchase blocks of pumping power enabling more real-time response to grid conditions [10].

In that context, it is requested to develop pump-turbines that reliably stand dynamic operation modes, fast changes of the discharge rate and with stability limits positioned considerably away from the normal operating range.

At off design conditions the wickets gates channel and the draft tube do not work properly and give awkward boundary conditions to the impeller, together with a strong fluid-dynamical interaction between rotor and stator parts [11-15]. The flow features such as separation and recirculation occur severely in an unsteady manner. Non-rotating components of the turbine, such as guide vanes, stay vanes, head cover, draft tube cone, and also on the hydraulic system, especially the penstock may experience strong dynamic load and high cycle fatigue stress 
that may result in the propagation of cracks and the failure of the shear pin or the guide vanes stem.

Frequency and time-frequency experimental analyses highlighted the existence of rotating structures of pressure pulsations at the runner exit appearing and disappearing in time, having greater intensity at part loads [16-20]. This strong rotor stator interaction (RSI) resulted to be further emphasized in multi-stage pump-turbines in which a 'full-load-instability' (FLI) develops in the range from 60 to $90 \%$ of the design flow rate [19] and quite independent to the rotational speed [17].

Recently, Li Deyou et al [21] focused the numerical analyses into the hump region trying to correlate the hump characteristics to the vortex motion in the tandem cascade.

Numerical analysis were also carried out by Gentner et al. [22] and Cavazzini $G$ et al. [23] highlighting, the dependence of the flow behaviour in the head drop from a perturbation of the wickets gates channel flow field, characterized by an unsteady flow rate migrations between passages and by unsteady flow jets.

The results at constant flow rate of both experimental and numerical analyses highlighted the existence of a spatial fluctuation pattern concentrated close to the runner exit, whose fluctuations levels increases at off-design conditions.

Even though these studies have allowed to obtain interesting information on the unstable behaviour of pump-turbines, to solve instability problems and to enlarge the working range of pump-turbine significantly, an in-depth understanding of the unsteady flow mechanism during power regulation is crucial for the production stabilization.

In this context, time domain simulation of the dynamic behaviour of the pump-turbine can provide useful insights for decision-making.

The aim of this investigation was to analyse the development of the unsteady phenomena of a reversible-pump turbine operating in pump-mode load following control function. The numerical analysis included the dynamic pressure measurements from best efficiency point (BEP) to part flow rate at a fixed gradient of the power reduction. The analysis of pressure fluctuations was conducted in both frequency and time frequency domains.

A 3D transient flow simulation in the entire pump-turbine was conducted to investigate the rotor-stator interaction by adopting the DES turbulence model. A commercial CFD programme was utilized to study the flow through this pumpturbine in its stationary and transient passages, from $100 \%$ optimum load to $70 \%$ of part load reduction by an adjustablespeed approach.

\section{NUMERICAL MODEL}

Numerical analyses were carried out by the commercial software ANSYS 15.0 on the first stage of a two stage reversible pump-turbine in pump-operating mode (fig. 1). Table 1 reports the main geometrical data of the considered pump-turbine. In the analysed configuration, the radial gap between the trailing edge of the guide vanes and the runner tip was $10.5 \mathrm{~mm}$, which is $5.25 \%$ of the impeller radius. The relative azimuthal position of the guide vanes was fixed by rotating the whole guide vane system from the face-to-face configuration $\left(\lambda=0^{\circ}\right)$ to the configuration with the azimuthal position of the guide vanes $+8^{\circ}$ out of alignment (fig. 2).

Moreover, fig. 2 shows some of the mid-height points were the unsteady pressure was recorder during the numerical

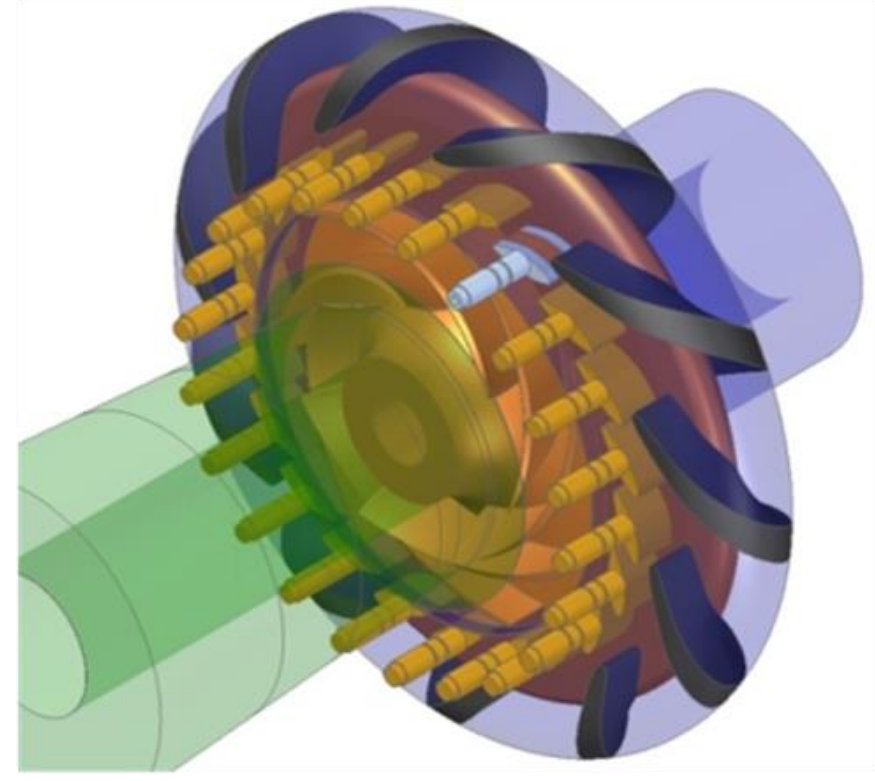

Fig. $13 \mathrm{D}$ scheme of the tested configuration.

Table 1 Geometry characteristics and performance parameters of the tested pump-turbine.

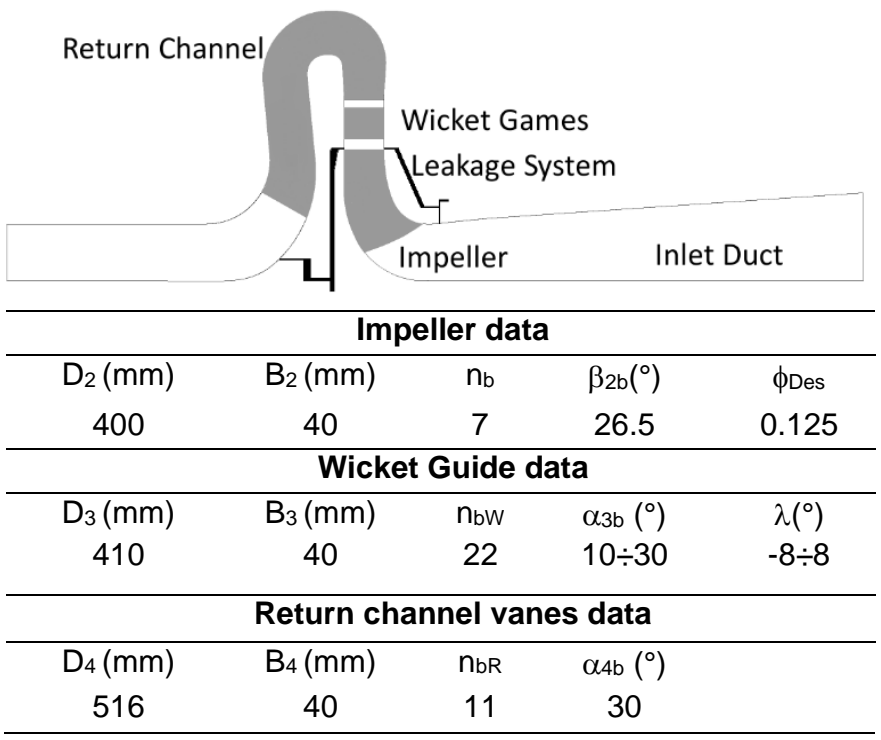

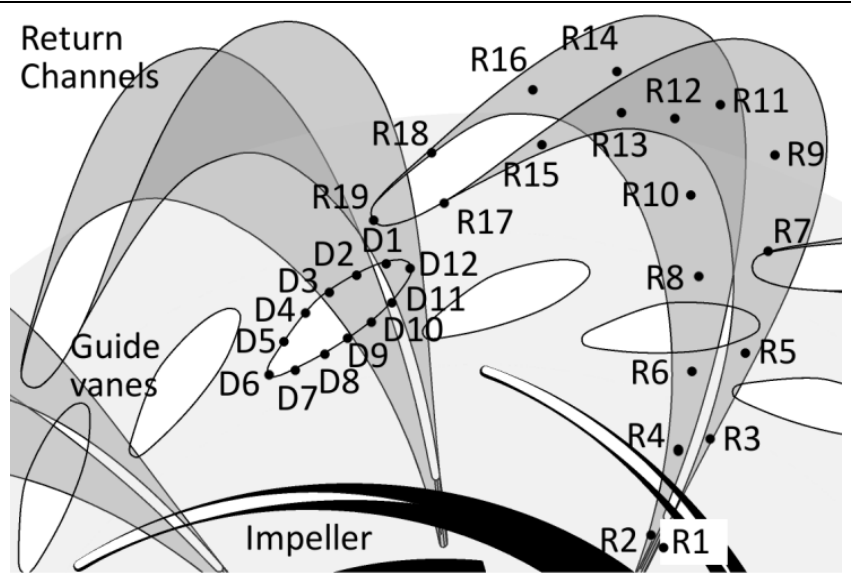

Fig. 2 Detail and sketch of the tested configuration $\left(\lambda=8^{\circ}\right)$ with the distribution of monitor points. analysis.

The numerical model of the entire machine included inlet duct, return channel, wicket vanes, runner, draft tube and 
leakage system.

The draft tube was discretized by a structured mesh of about 339500 elements with a $y+$ values lower than 20. As regards the runner, an $\mathrm{O}$ grid was performed. The stage head $\mathrm{H}$ and the stage efficiency were evaluated in preliminary tests to assure grid independent solution for the runner and to guarantee the capacity of numerical solution to capture the local pressure pulsations as well. Even if the sensitivity analysis highlighted a grid independent solution with about 200000 elements per passage, the intensity and the extent of the local pressure pulsations appeared to be correctly evaluated only with grid greater than 300000 elements per passage. To be sure of the capacity of the numerical solution to capture local pressure pulsations in the whole domain, as a precautionary measure, the adopted number of elements was further increased to 565000 . The resulting runner computational domain that was used had 3.96 million of cells with $y+$ values below 15 .

O-type grids were adopted for both the wicket gate and the return channel discretization. Following the same philosophy used for the impeller the number of elements was increased to about 4.3 and 5.4 million of cells, respectively. The leakage from the labyrinth seal was also considered and several $\mathrm{H}$-blocks were built to describe the cavities.

The choice of the turbulence model is a key issue in CFD. According to the large flow separations expected at part load, a Detached Eddy Simulation (DES) model was adopted. On both blades and end walls, the boundary layer were assumed fully turbulent. All the interfaces between statorrotor blocks were standard transient sliding interfaces.

At the inlet boundary condition, the total pressure was imposed with the values taken from the experimental data. At the outlet, due to the highly disturbed flow field, an opening condition with an average static pressure was fixed.

The power reduction was simulated by a time-varying boundary condition in which the impeller was slow down from $100 \%$ to $93 \%$ rpm corresponding from full load to about $70 \%$ of the full load with a ramp rate of $1.5 \%$ per second.

A second order implicit time stepping was adopted for the time discretization and a time step of $1^{\circ}$. The root mean square Courant number resulted to be lower than 1.9 for all the power, guaranteeing an accurate resolution of the transient details. The maximum resulting RMS values for the residuals were $u$ momentum $10^{-4}$, $v$ momentum $10^{-4}$, w momentum $3 \cdot 10^{-5}$, and turbulence kinetic energy $10^{-4}$.

\section{RESULTS}

\subsection{Validation of Numerical Mode at Constant Flow Rate conditions}

To validate the numerical model, the numerical head curve was compared with that experimentally acquired on the pump-turbine under test according to ISO standards.

Numerical analyses were carried out for some operating points at a constant rotation rate of $600 \mathrm{rpm}$. The numerical data were acquired for 5 impeller revolutions after more than 20 revolutions required to achieve a quasi-steady simulation convergence. The comparison in terms of head is reported in fig. 3. The agreement between average numerical and experimental results is good with an error smaller than $2 \%$ near the best efficiency point and smaller than about $4 \%$ at

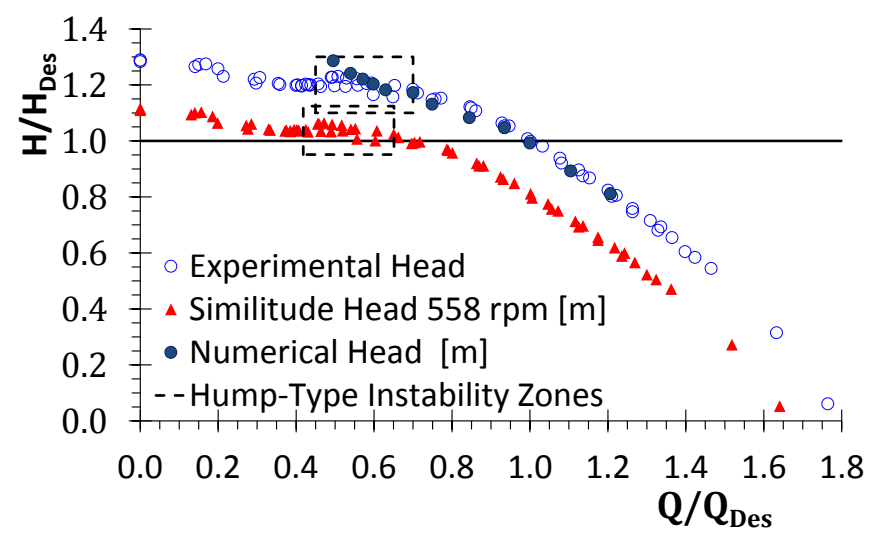

Fig. 3 Comparison between numerical and experimental head curves.

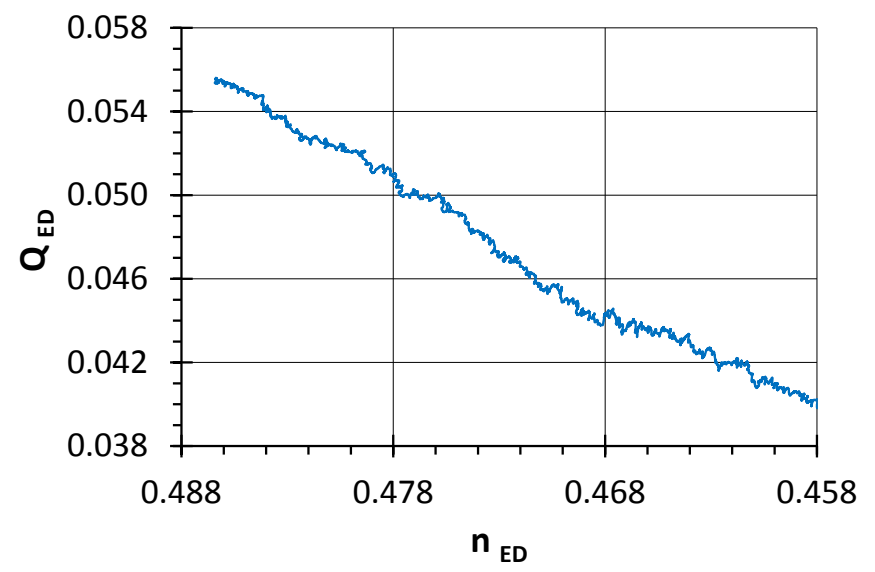

Fig. 4 Numerical dimensionless discharge-speed curve. 0.458

partial loads (fig. 3 ).

The good agreement in terms of mean values between numerical and experimental results demonstrated the capability of the numerical model to predict the performance of the pump-turbine with sufficient accuracy not only at BEP condition.

In fig. 3, the characteristic obtained by the similarity laws at $558 \mathrm{rpm}$ is shown. The lower impeller speed appears to guarantee a working range outside the hump zone and to avoid instabilities.

\subsection{Numerical Analysis of the Pump-Turbine in a Power Reduction Scenario}

To study the evolution of the flow field in a dynamic power reduction scenario the wicket vane was fixed at $18^{\circ}$ and kept constant during the simulation.

The transient numerical simulation on the entire machine was carried out with a time-varying boundary condition in which the impeller speed was reduced every time step whereas the total pressure at inlet and the average static pressure at outlet were maintained constant.

In this case, a simple linear variation of the impeller speed from $100 \%$ to $93 \%$ was fixed.

The initialization was based on the results of the steady simulation carried out for the BEP flow rate.

Fig. 4 reports the dimensionless factors during power reduction. The pump flow rate decreased progressively with limited oscillations only at lower impeller speed (fig.4). The flow field inside the impeller did not show instabilities up to the lower speed factor (fig. 5) and consistently, the flow rate inside in each impeller channel showed the same progressive and regular flow reduction highlighted for the pump (fig. 6). 


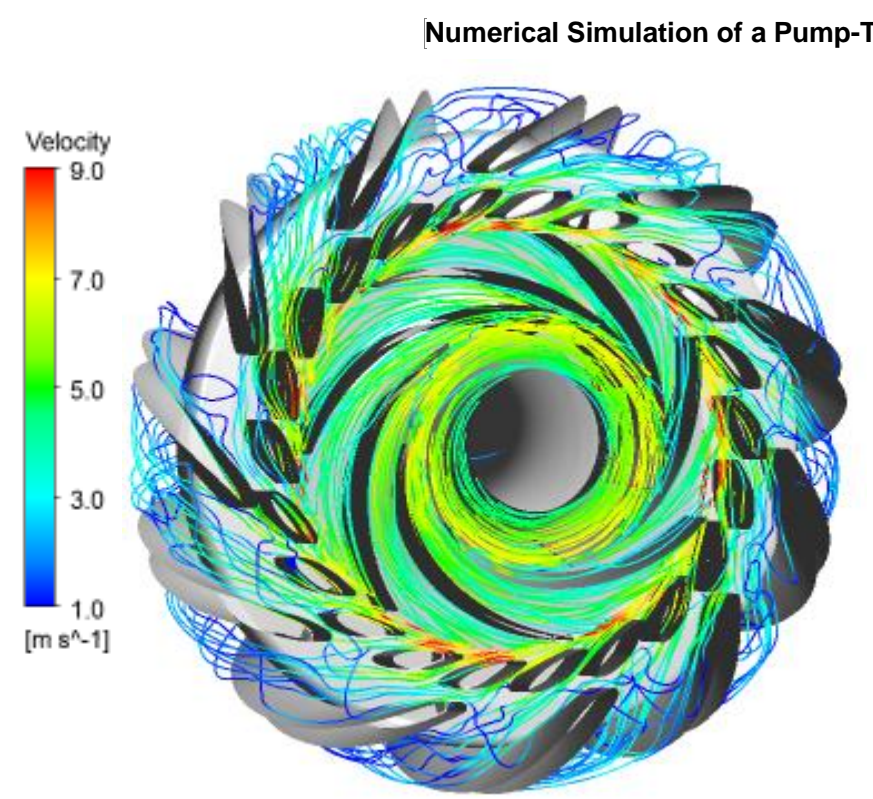

Fig. 5 Flow field inside the pump-turbine for $\mathrm{n}_{E D}=0.458$.

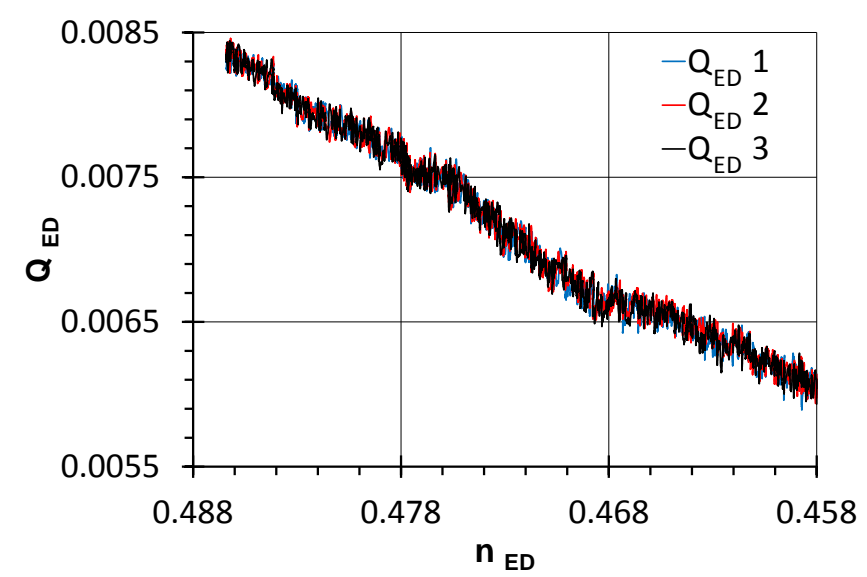

Fig. 6 Numerical dimensionless discharge-speed curves of three consecutive impeller channels.

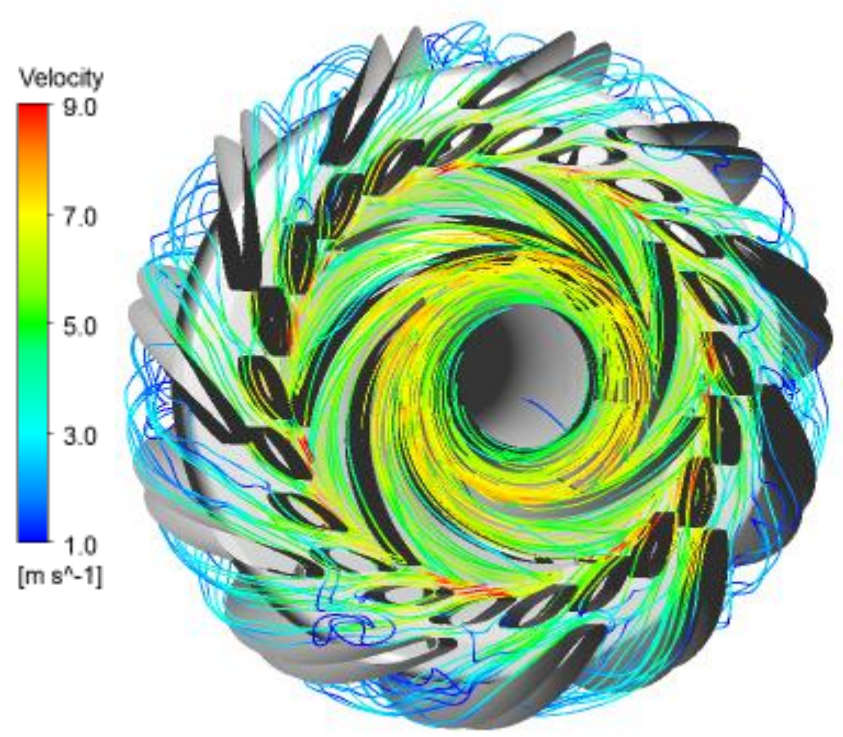

Fig. 7 Flow field inside the pump-turbine for $\mathrm{n}_{E D}=0.482$.

In the return channel, the flow field was perturbed by a sort of unsteady stall phenomena from the very beginning of the simulation with channels characterized by vortexes partially blocking the channels (fig. 7) and forcing the streamlines to climb over the reverse flow volume presents in the corner be-

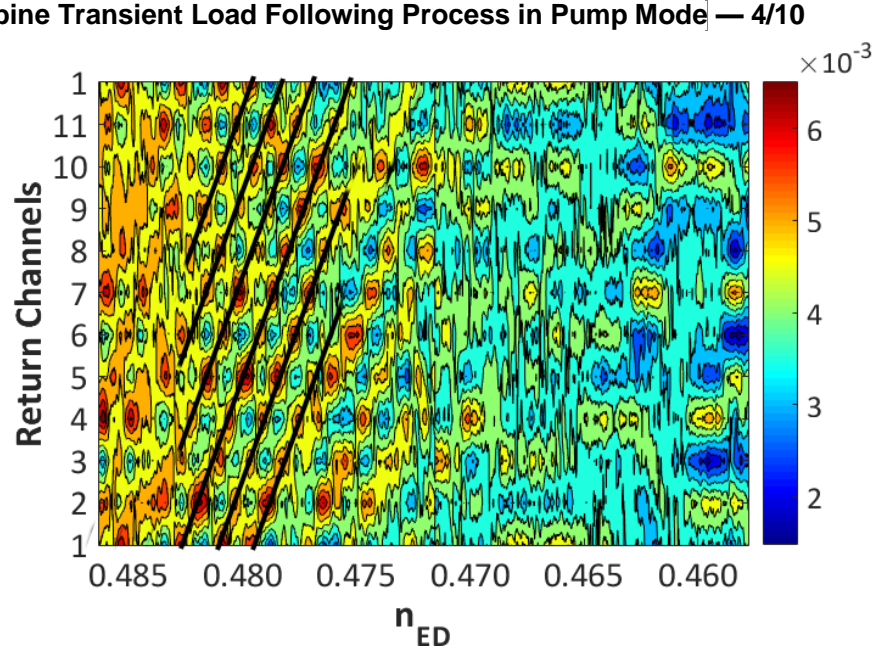

Fig. 8 Numerical dimensionless discharge-speed curves of the return channels.

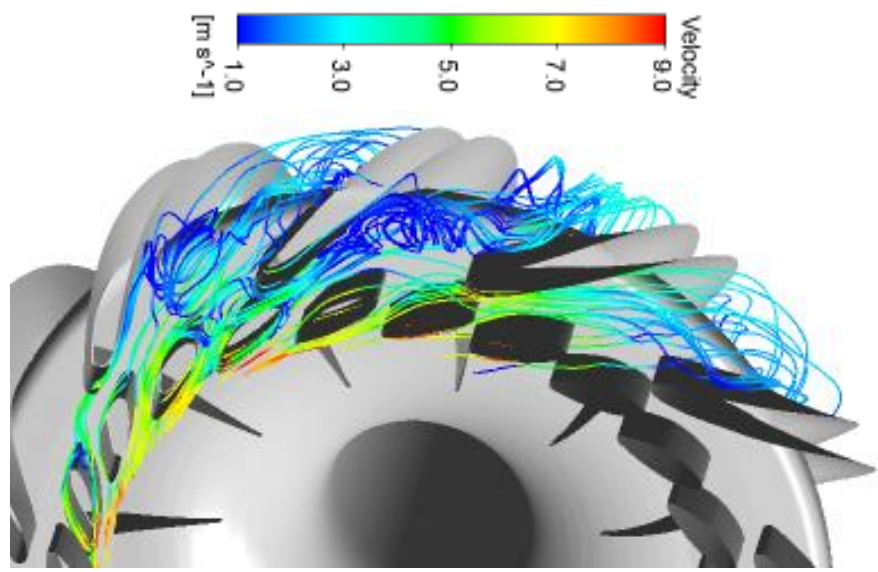

Fig. 9 Flow field inside the pump-turbine for $\mathrm{n}_{E D}=0.482$.

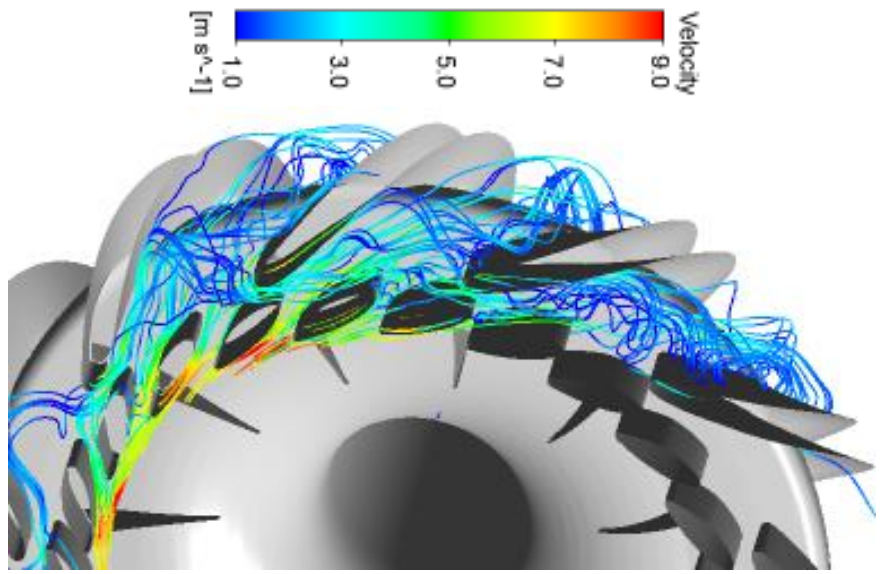

Fig. 10 Flow field inside the pump-turbine for $\mathrm{n}_{E D}=0.472$.

tween the vane suction side and the U-Turn hub.

The blockage action was confirmed by the analysis of the flow rate passing through the return channels (fig.8). Each return channel alternated between partially blocked and unblocked flow.

During the power reduction, the perturbation of the pumpturbine flow field evolves in a rotating partial stall of five cells moving from one channel to the subsequent one according to the runner rotation direction as highlighted in fig. 8 by the black lines.

The progressive decrease of the flow rate causes, in the first phase, the development and enlargement of the regions of flow separation (fig 9) and an increase of the flow rate oscil- 


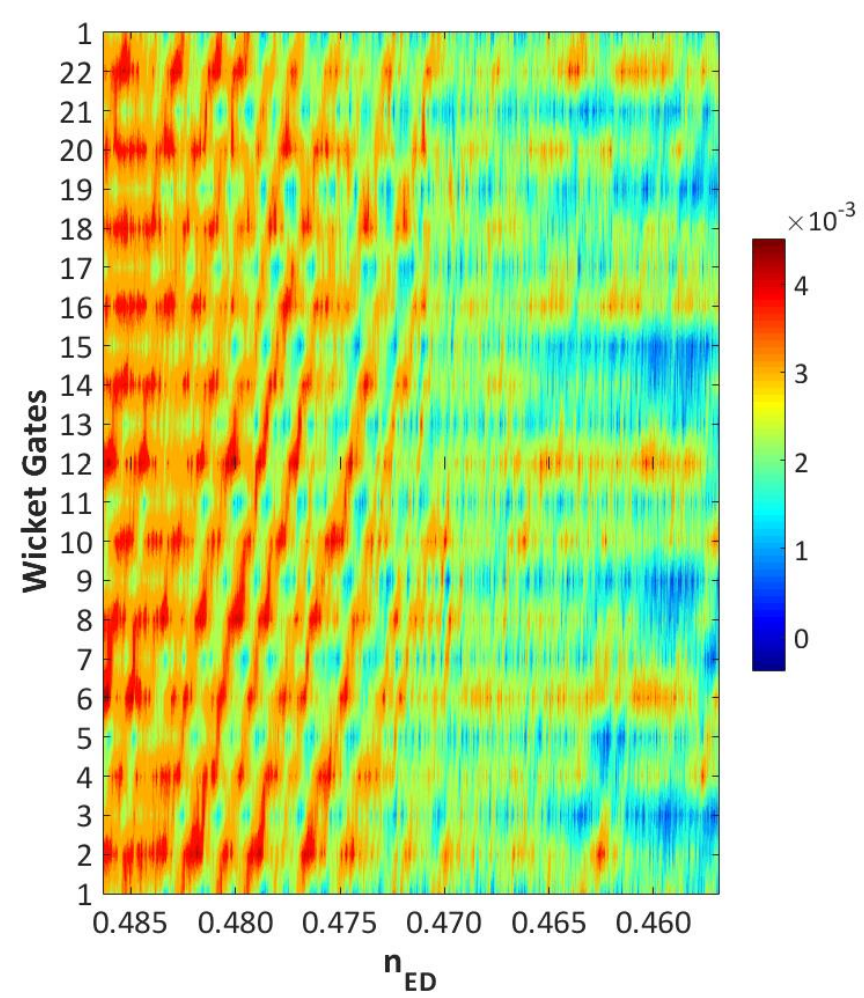

Fig. 11 Numerical dimensionless discharge-speed curves of the wicket gates.

lation (fig. 8).

Successively the organized partial stall lost the coherence, the stall breaks up progressively and the vortexes involves quite uniformly all the channels (figs 8 and 10).

At higher speed factors, the wicket gate channels experience flow rate oscillation (fig. 11) and eleven channels with low flow rate are alternated by eleven channels with higher flow rate.

Close to the hump zone, the blockage action involves two or three adjacent wicket gate channels (fig. 11) and the flow field evolves in a rotating partial stall of four cells moving from one group of channels to the subsequent one according to the runner rotation direction as highlighted in fig. 11.

Due to the rotating characteristics of the blocking cells, the vanes were characterized by time fluctuations of the pressure distributions and hence of the torque, depending on the evolution of the flow field around the blade. Fig. 12 reports the evolution of the pressure coefficient on five of the monitor points marked on the wicket gate of fig. 2, while fig. 13 shows the torque factor over time on a wicket gate during power reduction.

The history of the signals highlights two phases; in the first, up to about $\mathrm{n}_{\mathrm{ED}}=0.475$, low frequencies are more evident than in the second phase. Moreover, the pressure coefficient and the torque fluctuations on the blades increases in amplitude together with the impeller speed reduction.

The development of these unsteady phenomena in the stators affected the pressure distribution on the vanes, thereby modifying their load distribution and induces dynamic load on the shear pin or the guide vanes stem.

\subsection{Time-frequency characterization of the unsta- ble behaviour}

Spectral analyses in frequency and in time-frequency domain were carried out to characterize the unsteady phenomena
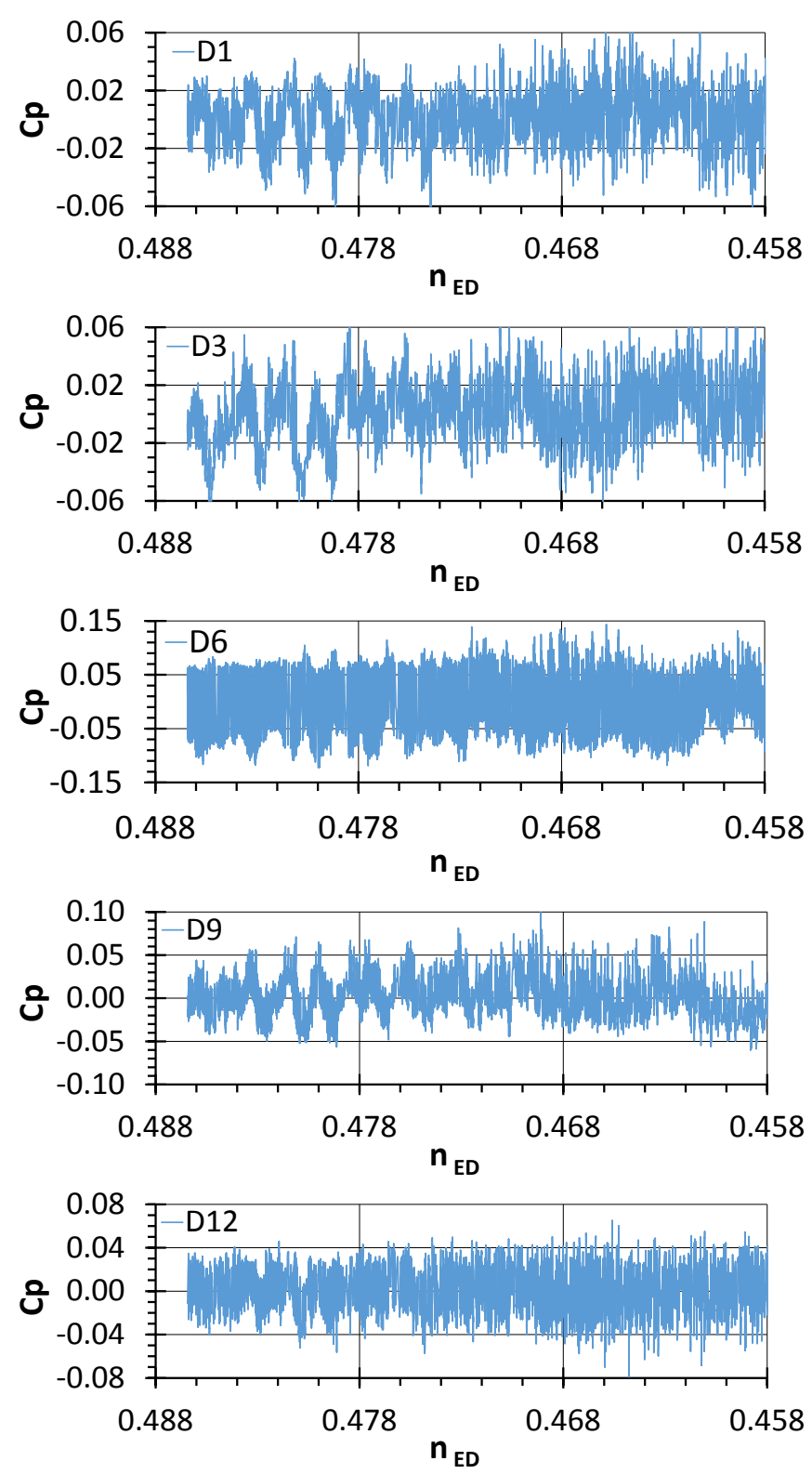

Fig. 12 Pressure coefficient versus speed factor acquired in the wicket gate.

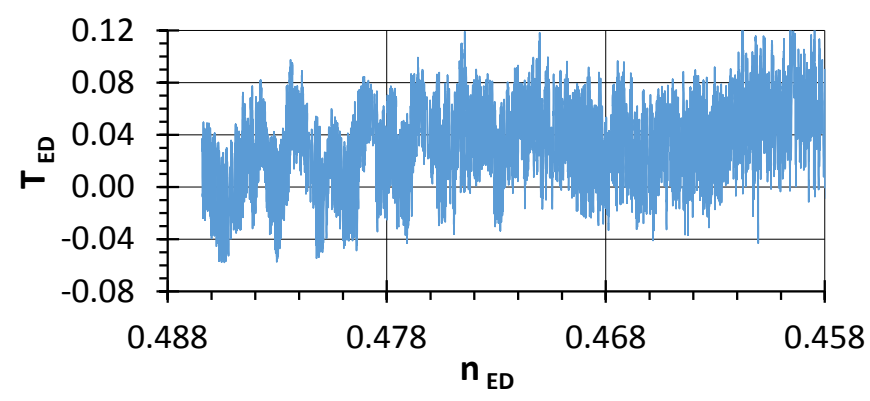

Fig. 13 Wicket gate torque factor versus speed factor.

identified in the previous flow field analysis [16].

The frequency content of the numerical signals, acquired at each time step during the whole simulation of power reduction, was determined by using a Hamming window in the Lomb periodogram.

Fig. 14 reports the power spectrum of the flow rate signal acquired in the return channel.

The spectrum is dominated by peaks at low frequency $(\mathrm{St}<0.1)$, whose amplitude is greater than that of the blade 


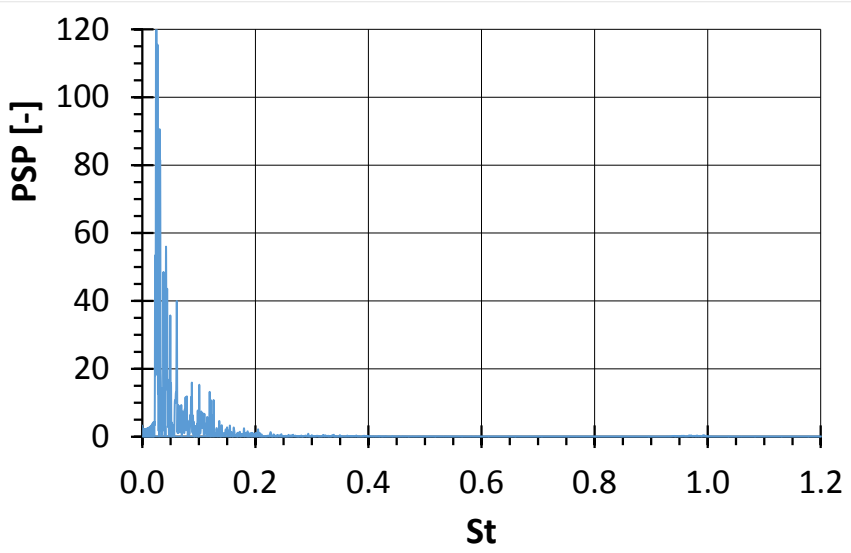

Fig. 14 Normalized power-spectra of the discharge factor acquired in the return channels 2 of fig. 2.

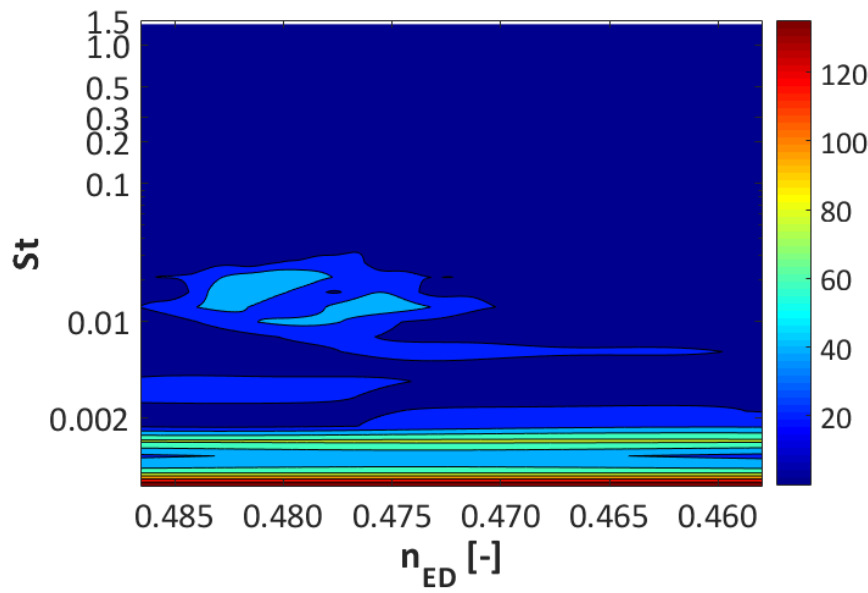

Fig. 15 Normalized power-spectra of the discharge factor acquired in the return channels 2 of fig. 2.

passage frequency $(\mathrm{St} \cong 1$ ).

The signal processing in the frequency domain makes it possible to analyse the spectral components contained in a signal, but it does not make assigning these spectral components to time feasible. In order to identify the instant and hence the operating condition in which the frequency characterizing the rotating block appears, a time frequency characterization was performed via wavelet transform analysis.

For all the series of data, the continuous wavelet transform $\mathrm{W}(\mathrm{s}, \mathrm{n})$ was computed via the FFT-based fast convolution according to the following equation:

$$
W\left(\mathrm{~s}, \mathrm{n}^{*}\right)=\sum_{\mathrm{k}=0}^{\mathrm{N}-1} \mathrm{X}_{\mathrm{k}}\left(\sqrt{\frac{2 \pi s}{\delta \mathrm{t}} \psi_{0}^{*}\left(s \omega_{\mathrm{k}}\right) \mathrm{e}^{\mathrm{i} \omega_{\mathrm{k}} \mathrm{n}^{8} \delta \mathrm{t}}}\right)
$$

where $X_{k}$ is the DFT (Discrete Fourier Transform) of the discrete sampled signal $X_{n}, k$ is a frequency index, $N$ is the length of the data series, $s$ is the wavelet scale, $\delta t$ is the sampling interval, $\mathrm{n}^{*}$ is the localized time index. $\Psi^{*}{ }_{0}(\mathrm{~s} \omega \mathrm{k})$ is the complex conjugate of the Fourier transform of the scaled version of the "mother wavelet" $\psi(t)$ and $\omega_{k}$ is the angular frequency (note that if $k \leq N / 2, \omega_{k}=2 \pi k / N \delta t$; else $\omega_{k}=-$ $2 \pi k / N \delta t)$. The normalization factor was introduced to obtain a unit energy at each scale. As regards the choice of the mother wavelet, in this case, a complex Morlet wavelet with $2 \pi f_{0}=8$ was chosen.

Fig. 15 reports the continuous wavelet transform of the signals of the flow rate passing through the return channels 2 .

The frequency, corresponding to the flow variation, is clearly identifiable, and starts to appear from nearly the BEP flow
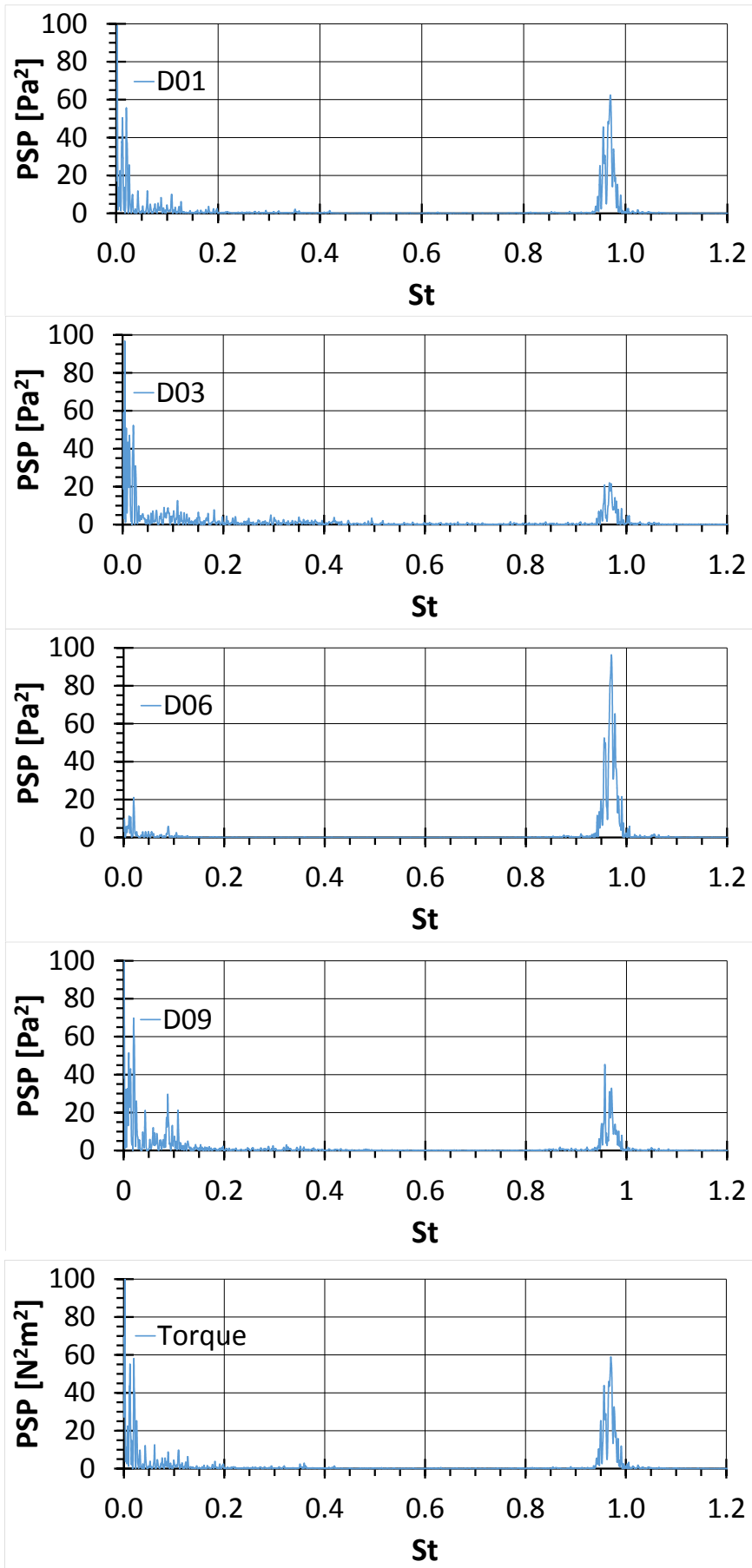

Fig. 16 Normalized power-spectra of pressure and torque signal acquired on the wicket gate.

rate. The intensity of the flow variation reached a maximum after about a power reduction of the $11 \%$. With further reduction of the impeller rotational speed, the flow field perturbation into the pump turbine evolves and the organized rotating stall disappears replaced by a flow fluctuation dominated by a very low frequency (St $\leq 0.01)$.

The BPF is weakly appearing in the spectrum consistently with the uniform and regular flow field into the impeller.

These remarks are confirmed by the normalized powerspectra of pressure and continuous wavelet transforms calculated for the signals acquired in the stator domains, some of which are reported from fig. 16 to fig. 20 .

The blade passage frequency is captured, with more or less intensity during the whole load rejection simulation, in the fre- 


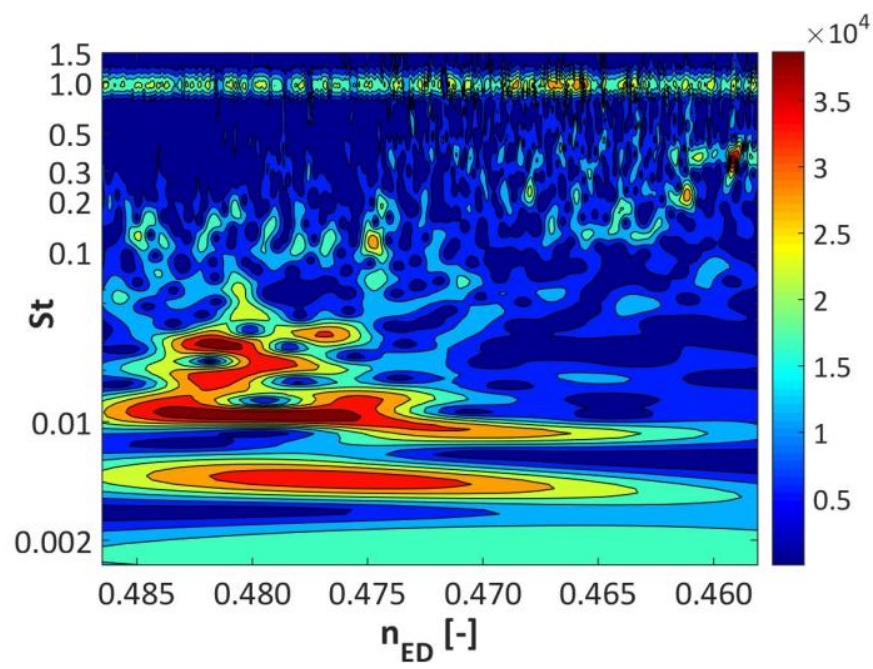

Fig. 17 Normalized power-spectra of pressure signal acquired in the wicket gate monitor point D12 of fig.2.

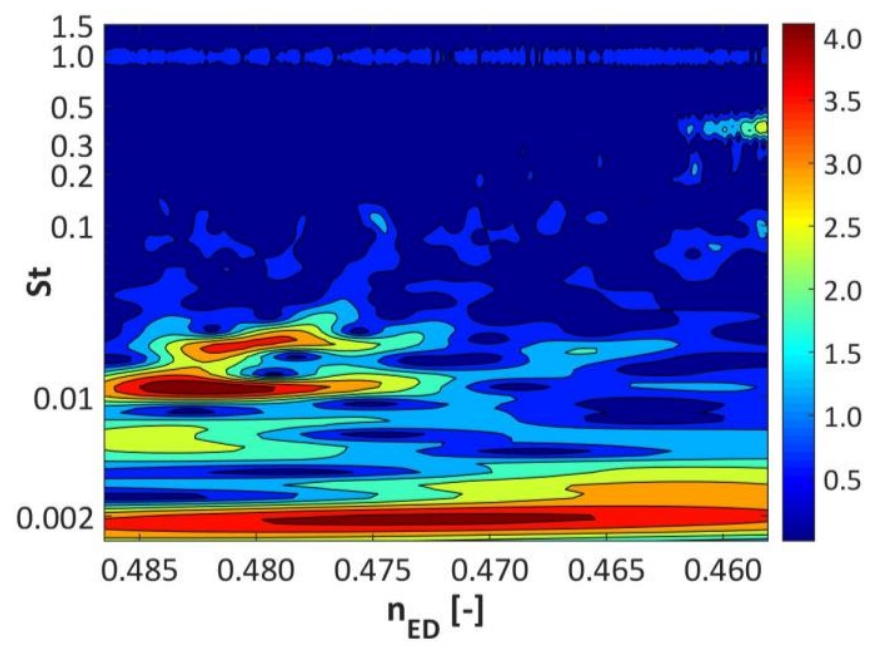

Fig. 18 Normalized power-spectra of torque signal of a wicket gate.

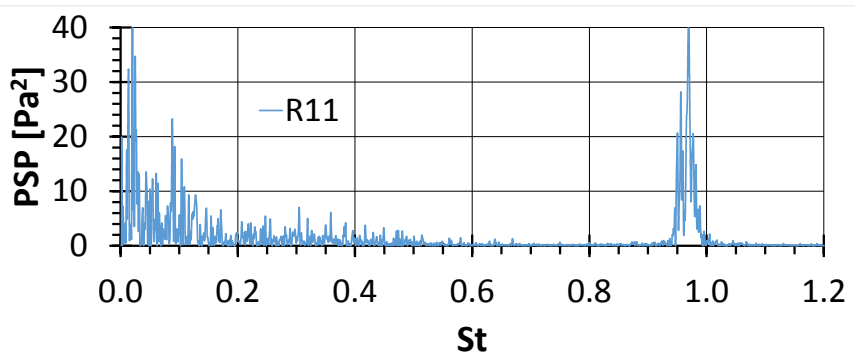

Fig. 19 Normalized power-spectra of pressure signal acquired on the wicket gate.

quency and time frequency transforms of the signals of the static pressure and of the torque acting on the wicket vanes (figs 16 - 20).

At the wicket blade leading edges, due to the proximity of the runner outlet, the pressure pulsation, caused by the rotation of the impeller blades, is strongly perceived by the guide vanes, dominating the resulting power spectrum (fig. 16). Vice versa, the spectral characterization of the sections far from the impeller demonstrates a relationship between the appearance of a well-defined frequency in the spectral content of the machine and the fluid-dynamical evolution of the unsteady phenomena during the power reduction.

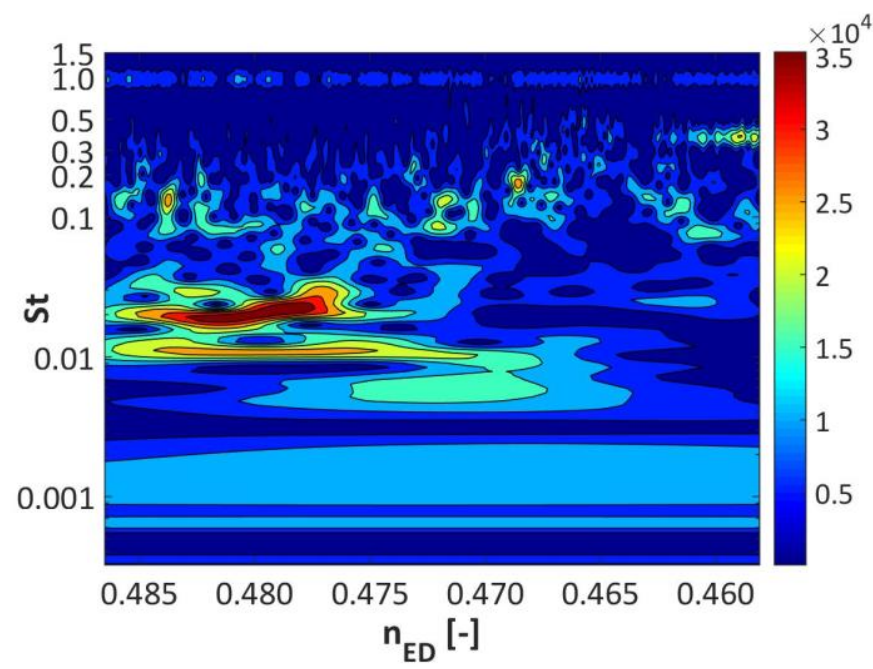

Fig. 20 Normalized power-spectra of pressure signal acquired in the return channel monitor point R11 of fig.2.

First, the perturbation of the pump-turbine flow field evolves in an organized rotating partial stall. This instability induces lobs of pressure fluctuations and dynamic load on the shear pin or the guide vanes stem.

Successively, the back flow volumes in the return vane channels become quite stable. The flow rate tend to remain quite constant in all the return channels (fig. 8) and the flow path does not change evidently (figs 20 and 21). The path analyses show only vortexes witch intensity and structure changed to a limited extent.

Consistently, the stator elements experience a phase of limited dynamic loads or actions as the figures 17, 18 and 20 highlighted into the speed factor range 0.47-0.46.

A further reduction of the impeller speed forces the pump to work close to the hump zone (fig.3).

Fig. 22 presents the streamlines evolution into each wicket gate channel during impeller revolutions.

The nuclei were not stable and when they appeared the time frequency analyses highlighted the start-up of pressure and torque oscillations at a frequency close to $\mathrm{St}=0.33$ (Figs 17, 18 and 19).

This unsteadiness is in agreement with the evolution a full three-dimensional flow structure into the wickets gates channel visualized experimentally [25] in the hump zone.

\section{CONCLUSIONS}

Numerical analyses were carried out on a low specific speed pump-turbine, operating at full and part load conditions on pump mode. The pressure and the torque variation in time and frequency domains were used to analyse the flow field when the impeller was slow down from $100 \%$ to $93 \%$ rpm corresponding to a power reduction from full load to about $70 \%$ with a ramp rate of $1.5 \%$.

The different unsteady patterns were highlighted coherently by both spectral and bispectral analysis of the pressure data.

When the flow rate decreased below the BEP flow rate, stall cells, partially blocking the regular flow, moves from one channel to the subsequent one in the runner rotation direction with increasing intensity during the load rejection. Each runner channel alternates partial blocked flow according to the rotation frequency of the stall cell. The unsteady pattern in return channel strengthened emphasizing its characteristic frequency with the rotational velocity decreasing reaching a maximum 

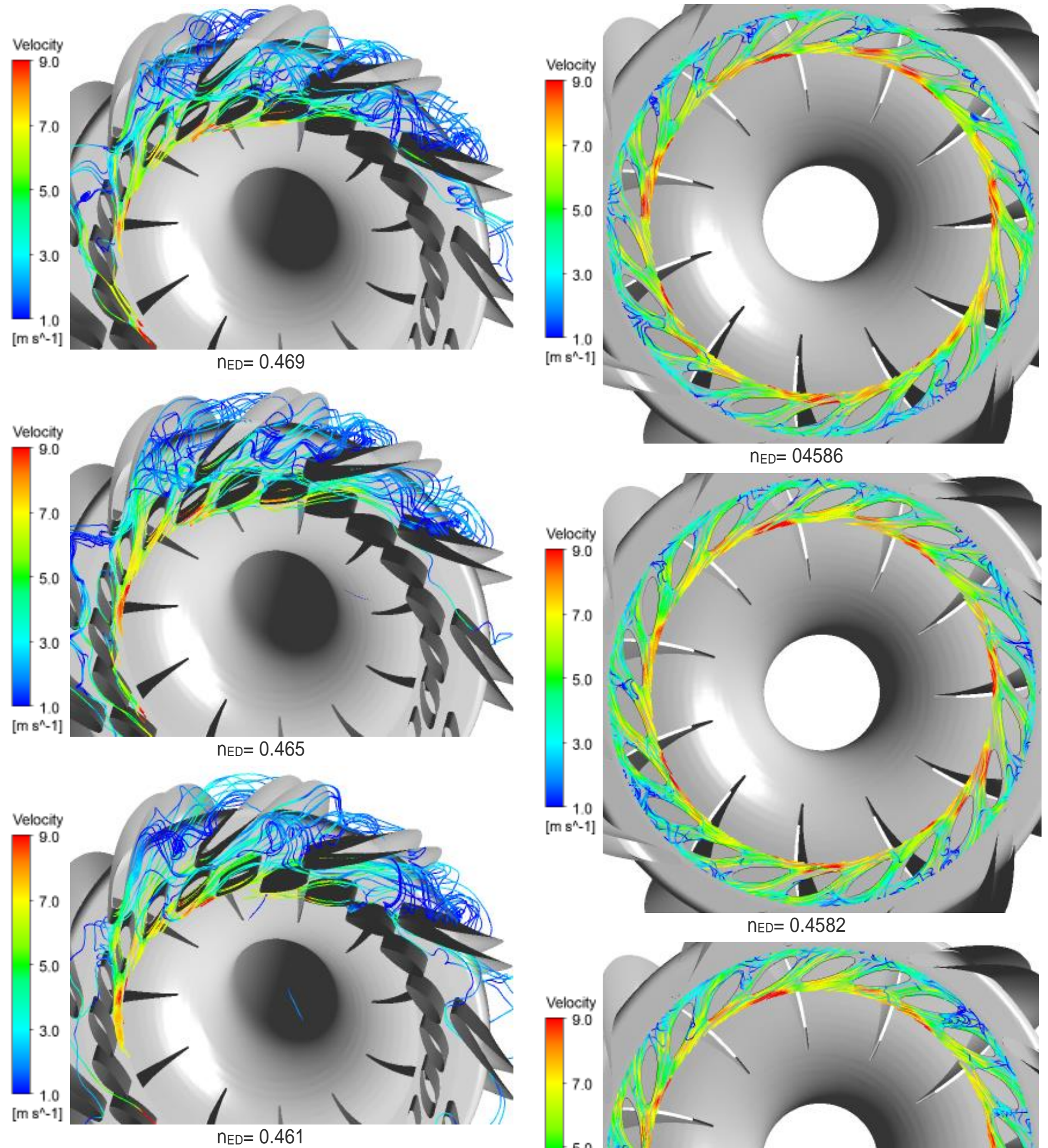

Fig. 21 Flow field inside the pump-turbine at different speed factor.

and then disappearing.

For lower rotational speed, the periodic back flow inside the return channel disappeared. The path analyses show only vortexes with intensity and structure changed stochastically.

At lower rotational speed, the flow field into the wickets gates channel start to manifest a full three-dimensional flow structure. This disturbance was related to the boundary layer separation and stall was noticed with a frequency very close to $S t \approx 0.335$ identified by experimental measured.

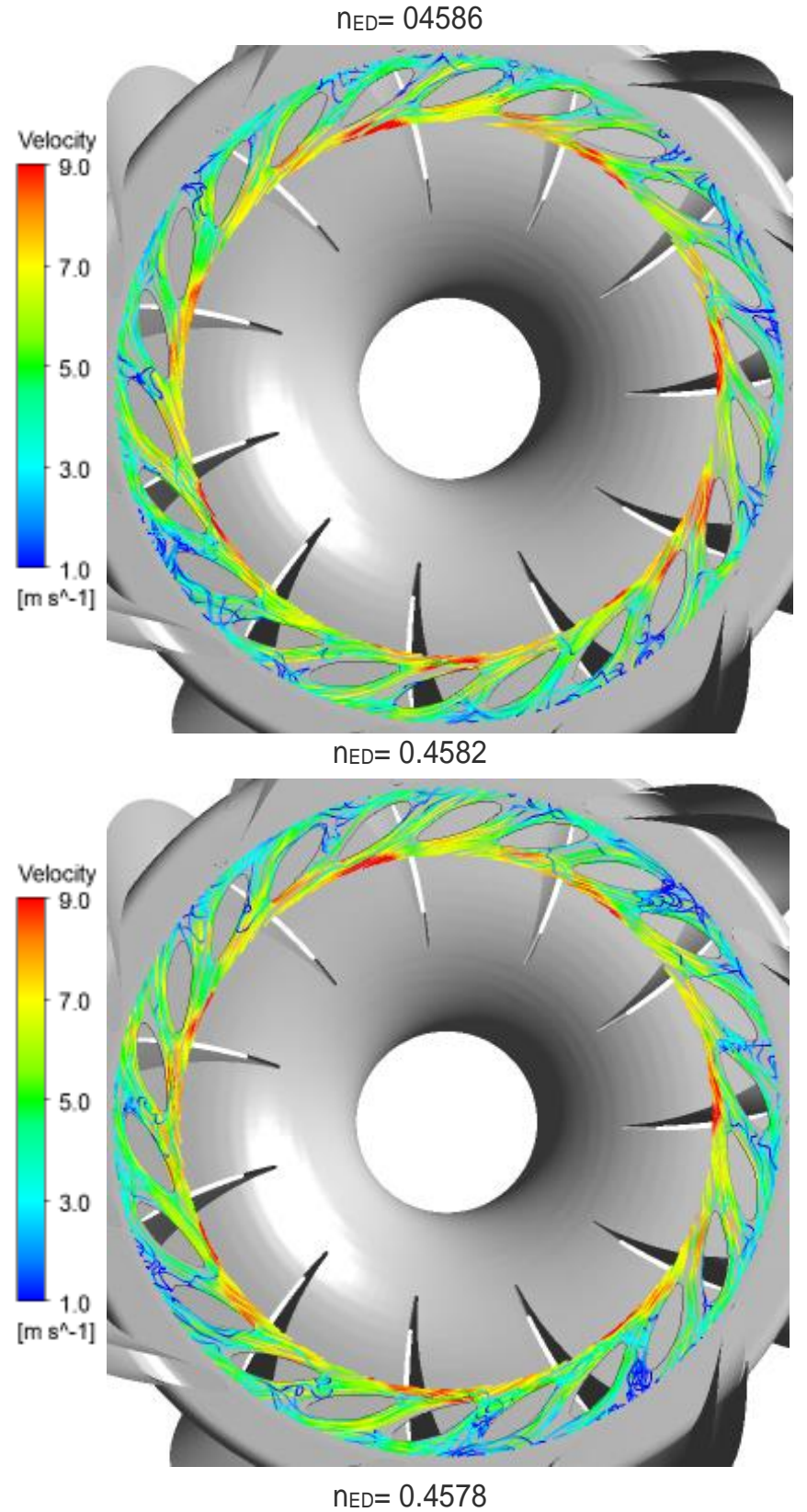

Fig. 22 Flow field inside the wicket gates. 


\section{NOMENCLATURE}

B

$c_{p}=\frac{p-\bar{p}}{\rho\left(\omega \frac{D_{2}}{2}\right)}$
$\mathrm{D}$
$\mathrm{g}$
$\mathrm{GXx}$
$\mathrm{n}$
$\mathrm{n}_{\mathrm{ED}}=\frac{\mathrm{nD}_{2}}{\sqrt{\mathrm{gH}}}$

$\mathrm{n}_{\mathrm{b}}$

$\mathrm{n}_{\mathrm{bR}}$

$\mathrm{n}_{\mathrm{bW}}$

Q

$\mathrm{p}$

$\overline{\mathrm{p}}$

$\mathrm{Q}_{\mathrm{ED}}=\frac{\mathrm{Q}}{\mathrm{D}_{2}^{2} \sqrt{\mathrm{gH}}}$

$\mathrm{BPF}=\frac{\mathrm{n}_{\mathrm{b}} \mathrm{n}}{60}$

$\mathrm{St}=\frac{\mathrm{f}}{\mathrm{BPF}_{\text {Des }}}$

$\mathrm{T}_{\mathrm{ED}}=\frac{\mathrm{T}}{\rho \mathrm{D}_{2}^{3} \mathrm{gH}}$

$\alpha$

$\beta$

$\lambda$

$\omega$
Impeller or guide vane or

return channel width

Pressure coefficient

Diameter

Gravitational acceleration

Power spectra

Head

Rotational speed of the impeller

Impeller number of blades

Return Vane number of

blades

Wicket Guide number of

blades

Flow rate

Pressure

Pressure averaged along the time

Discharge factor

Blade Passage Frequency

Strouhal number

Torque factor

Angle

Angle

Guide vanes' azimuthally

position

Angular rotational velocity
Speed factor

m

$\mathrm{m}$

$\mathrm{m} \mathrm{s}^{-2}$

[]$^{2}$

$\mathrm{m}$

rpm

$\mathrm{m}^{3} \mathrm{~s}^{-1}$

$\mathrm{Pa}$

$\mathrm{Pa}$

$\mathrm{Hz}$

degree

degree

degree

$\operatorname{rad~s}^{-1}$

\section{Subscript}

2

3

4

b

Des outlet impeller

inlet wicket gate

inlet return channel

blade

Design Rotational speed of the impeller

\section{REFERENCES}

[1] SET-Plan Information System (SETIS) (2011), Electricity storage in the power sector, JRC European Commission.

[2] Arantegui, R., Fitzgerald, N., Leahy, P. (2012): Pumpedhydro energy storage: potential for transformation from single dams. European Commission, Joint Research Centre (JRC). Netherlands.

[3] European Commission (2012): Renewable energy targets by 2020 . Available from: http://ec.europa.eu/energy/renewables/targets_en.htm.

[4] Grotenburg, K., Koch, F., Erlich, I., Bachmann, U., "Modelling and Dynamic Simulation of Variable Speed Pump Storage Unit Incorporated into the German Electric Power
System", EPE 2001, Graz, Austria, 2001.

[5] Hodder, A., "Double-fed asynchronous motor-generator equipped with a 3-level VSI cascade", Thesis EPFL n² 2939, Switzerland,

Lausanne (http://library.epfl.ch/theses/?nr=2939), 2004.

[6] Kopf, E., Brausewetter, S., Giese, M., Moser, F., "Optimized control strategies for variable speed machines," In Proceeding of the 22nd IAHR Symposium on Hydraulic Machinery and Systems, Stockholm, Sweden, June -July 2004.

[7] Kuwabara, T., Shibuya, A., Furuta, H., Kita, E., Mitsuhashi, K., "Design and Dynamic Response Characteristics of 400 MW Adjustable Speed Pumped Storage Unit for Ohkawachi Power Station", IEEE Transactions on Energy Conversion, vol. 11, issue 2, pp. 376-384, June 1996.

[8] Schwery, A., Fass, E., Henry, J.-M., Bach, W., Mirzaian, A., "Pump storage power plants, ALSTOM's long experience and technological innovation", Hydro 2005, Villach, Austria, 2005.

[9] Simond, J. J., Sapin, A., Schafer, D., "Expected benefits of adjustable speed pumped storage in the European network", Hydropower into the next century, pp. 579-585, Gmunden, Austria , 1999.

[10] Henry J.M., Houdeline J.B., Ruiz S., Kunz T. (2012) How reversible pump-turbines can support grid variability - The variable speed approach. HYDRO 2012 Innovative Approaches to Global Challenges, 29-31 October 2012, Bilbao, Spain.

[11] Yuekun Sun, Zhigang Zuo, Shuhong Liu, Jintao Liu, and Yulin Wu (2014) Distribution of Pressure Fluctuations in a Prototype Pump Turbine at Pump Mode, Advances in Mechanical Engineering Volume 2014, Article ID 923937.

[12] Hui Sun; Ruofu Xiao; Weichao Liu; Fujun (2013) Wang Analysis of $S$ Characteristics and Pressure Pulsations in a Pump-Turbine With Misaligned Guide Vanes, J. Fluids Eng.. 2013; 135(5), 051101-051101-6. FE-12-1122, doi: $10.1115 / 1.4023647$.

[13] Li, W. (2012) Numerical investigation of pump-turbines with different blades at pump conditions, Journal of advanced manufacturing systems [0219-6867] vol. 11(2), pp 143-153.

[14] Rodriguez C.G., Mateos-Prieto B, and Egusquiza E Monitoring of Rotor-Stator Interaction in Pump-Turbine Using Vibrations Measured with On-Board Sensors Rotating with Shaft, Shock and Vibration, Volume 2014 (2014), Article ID 276796.

[15] Gentner C., Sallaberger M., Widmer C., Barun O., Staubli T. (2012) Analysis of unstable operation of pump turbines and how to avoid it, HYDRO 2012 Innovative Approaches to Global Challenges, 29-31 October 2012, Bilbao, Spain.

[16] Pavesi G., Cavazzini G., Ardizzon G. (2008) Timefrequency characterization of the unsteady phenomena in a centrifugal pump. Int. J. Heat Fluid FL, 29, pp. 1527-1540, DOI: 10.1016/j.jheatfluidflow.2008.06.008

[17] Pavesi G., Cavazzini G., Ardizzon G. (2008) Timefrequency characterization of rotating instabilities in a centrifugal pump with a vaned diffuser, International Journal of rotating Machinery, Vol. 2008 , DOI: 10.1155/2008/202179

[18] Cavazzini G., Pavesi G., Ardizzon G., Dupont P., Coudert S., Caignaert G., Bois G. (2009) Analysis of the rotor-stator interaction in a radial flow pump. La Houille Blanche, Revue Internationale de l'eau, 2009, 5, pp. 141-151, DOI 10.1051//hb/2009067

[19] Yang J, Pavesi G, Cavazzini G, Yuan S (2013) Numerical characterization of pressure instabilities in a vaned centrifu- 
gal pump under part load condition. IOP Conf. Ser.: Mater. Sci. Eng. 52 0022044, 6th International Conference on Pumps and Fans with Compressors and Wind Turbines (ICPF2013), DOI: 10.1088/1757-899X/52/2/022044.

[20] Yang J., Pavesi G., Yuan S., Cavazzini G., Ardizzon G. (2015) Experimental characterization of a pump-turbine in pump mode at hump instability region, Journal of Fluids Engineering, Vol 137,(4) (2015), DOI: 10.1115/1.4029572

[21] Li Deyou, Wang Hongjie, Xiang Gaoming, Gong Ruzhi, Wei Xianzhu, Liu Zhansheng (2015) Unsteady simulation and Analysis for hump characteristics of a pump turbine model, Renewable Energy, 77 (2015), pp. 32-42, DOI: 10.1016/j.renene.2014.12.004.

[22] Gentner C., Sallaberger M., Widmer C., Braun O., Staubli T. (2012) Numerical and experimental analysis of instability phenomena in pump turbines 26th IAHR Symposium on Hydraulic Machinery and Systems 15 (2012) 032042 doi:10.1088/1755-1315/15/3/032042

[23] Cavazzini G., Pavesi G., Ardizzon G. (2011) Pressure instabilities in a vaned centrifugal pump, Proceedings of the Institution of Mechanical Engineers, Part A: Journal of Power and Energy, 225(7), pp. 930-939

[24] Pavesi G., Cavazzini G., Jun Yang, Ardizzon G. (2014) Flow Phenomena Related to the Unstable EnergyDischarge Characteristic of a Pump-Turbine in Pump Mode 15th International Symposium on Transport Phenomena and Dynamics of Rotating Machinery, ISROMAC15 February 24 - 28, 2014, Honolulu, HI, USA.

[25] Pavesi G., Jun Yang, Cavazzini G., Ardizzon G. (2015) Experimental Analysis of Instability Phenomena in a HighHead Reversible Pump-Turbine at Large Partial Flow Condition, 11th European Conference on Turbomachinery Fluid Dynamics and Thermodynamics, ETC 2015 